\title{
Study on the Emotional Stress of Students of the Kolej Canselor (KC), Universiti Putra Malaysia During the Movement Control Order (MCO) of Pandemic Covid-19
}

\section{Amini Amir Abdullah \& Mohd. Daud Awang}

To Link this Article: http://dx.doi.org/10.6007/IJARBSS/v11-i12/11780

DOI:10.6007/IJARBSS/v11-i12/11780

Received: 06 October 2021, Revised: 10 November 2021, Accepted: 27 November 2021

Published Online: 16 December 2021

In-Text Citation: (Abdullah \& Awang, 2021)

To Cite this Article: Abdullah, A. A., \& Awang, M. D. (2021). Study on the Emotional Stress of Students of the Kolej Canselor (KC), Universiti Putra Malaysia During the Movement Control Order (MCO) of Pandemic Covid-19. International Journal of Academic Research in Business and Social Sciences, 11(12), 361-380.

Copyright: @ 2021 The Author(s)

Published by Human Resource Management Academic Research Society (www.hrmars.com)

This article is published under the Creative Commons Attribution (CC BY 4.0) license. Anyone may reproduce, distribute, translate and create derivative works of this article (for both commercial and non0-commercial purposes), subject to full attribution to the original publication and authors. The full terms of this license may be seen at: http://creativecommons.org/licences/by/4.0/legalcode

Vol. 11, No. 12, 2021, Pg. $361-380$

Full Terms \& Conditions of access and use can be found at http://hrmars.com/index.php/pages/detail/publication-ethics 


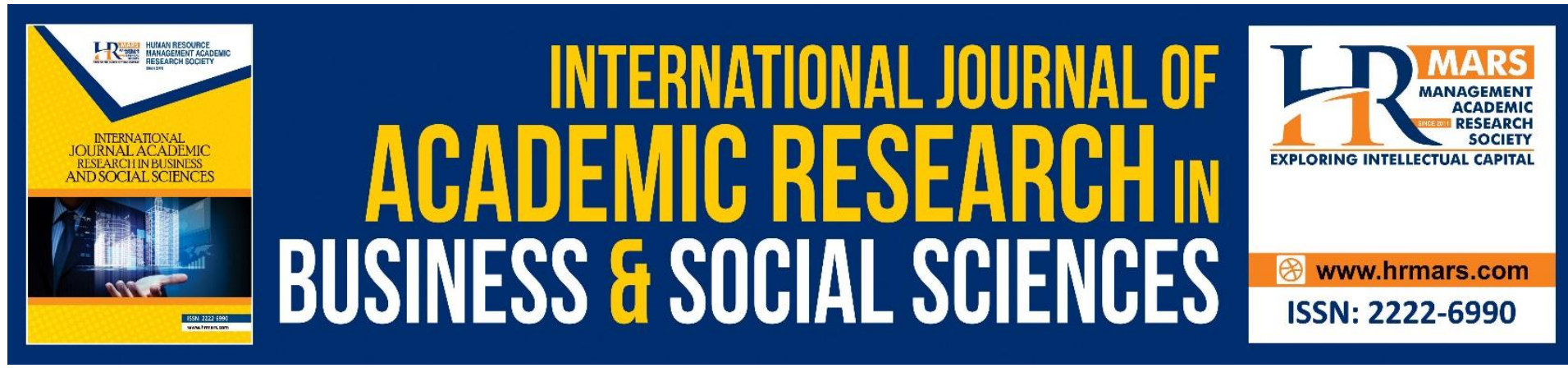

\title{
Study on the Emotional Stress of Students of the Kolej Canselor (KC), Universiti Putra Malaysia During the Movement Control Order (MCO) of Pandemic Covid-19
}

\author{
Amini Amir Abdullah \& Mohd. Daud Awang \\ Department of Government and Civilization Studies, Faculty of Human Ecology, \\ Universiti Putra Malaysia, 43400 Serdang, Selangor. \\ Email: amini@upm.edu.my
}

\begin{abstract}
This study is about the campus life of Kolej Canselor (KC) students, Universiti Putra Malaysia (UPM) during the Movement Control Order (MCO) from 18 March 2020 to 14 April 2020. The aspects examined are the value of patience, level of mental, emotional and psychosocial wellbeing among KC students during the period of the Covid-19 Movement Control Order (MCO). This study aims to identify the social support and diversity approach needed by students during the MCO. This research used quantitative method to obtain data when the Covid-19 pandemic is at an alarming level. The study involved $136 \mathrm{KC}$ students staying at the Kole Canselor residential college, UPM and found that $24.3 \%$ of students felt depressed during the period. A total of $13.7 \%$ of respondents stated that their level of depression was high compared to low and interestingly, $47.8 \%$ stated that they would like to return to their hometown if allowed. The students experienced something new during the MCO which they had never felt before. The KC management has provided various assistance services to the students while the Student Affairs Division has provided support services such as counseling services to help the psychological impact of the students during the MCO period.
\end{abstract}

Keywords: Emotional Stress, Students, Universiti Putra Malaysia (UPM), Movement Control Order (MCO), Pandemic Covid-19

\section{Background of Research}

In December 2019, the phenomenon of pneumonia appeared in the South Chinese seafood market in Wuhan, Hubei Province, China (Huang et al. 2020). The Chinese government later detected the phenomenon to stem from the Novel Coronavirus which was later renamed COVID-19 (also known as 2019-nCoV).

COVID-19 cases were detected in Malaysia on 23 January 2020 when the Ministry of Health $(\mathrm{MOH})$ through the National Crisis Preparedness and Response Center (CPRC) received reports of three cases suspected to be infected with COVID-19. On January 31, 2020, the World Health Organization (WHO) declared the COVID-19 pandemic a world health 
emergency. YAB. The Prime Minister of Malaysia, Tan Sri Muhyiddin Yassin then announced the Movement Control Order (MCO) for 14 days from 18 March 2020 to 31 March 2020, and then extended for Phase 2 from 1 April to 14 April 2020 and further extended for Phase 3 starting 15 April 2020 to 28 April 2020. As of 17 April 2020, there were 5251 cases of COVID19 infection in Malaysia with 86 deaths, cases being treated (2198) and total discharges (2697).

The nationwide COVID-19 pandemic has had a significant impact on the socio-economic development, education and higher learning sector and the social aspects of Malaysia. As the backbone of Malaysian society, universities in Malaysia were also affected when the Movement Control Order (MCO) was enforced. As many as more than 80,000 students of institutions of higher learning (IPT) were "trapped" in their hostels and residential colleges when the MCO was implemented. Higher Learning Institutions in Malaysia have played a positive role in the prevention and control of the COVID-19 pandemic. They have made important contributions to the emergency risk management including looking after the welfare, health and needs of students. Advice and counseling services are also provided to students on campus and off campus.

However, the psychological, emotional and psychosocial effects faced by students while living in a dormitory during a relatively long period of MCO and spending most of the time on campus can cause different psychological effects depending on how one reacts to the situation. On the positive side, some can have a positive psychological impact such as improving social relationships with hostel residents living in the same environment. However, for some students, the negative psychological effects are such as increased stress due to not being able to perform daily routines and activities outside the dormitory, not being able to meet parents, relatives, friends, worries and anxiety due to loss of "freedom", not being able to attend physically the lecture for example; to help loved ones, helplessness, boredom, loneliness and depression.

Mental health is part of a student's overall health. Signs that indicate a person's mental health is affected and in need of psychosocial support can be identified empirically. In fact, one can monitor their own mental health. Whether one's mental health is good or not depends on symptoms such as drastic changes in sleep patterns (e.g. insomnia), changes in appetite, extreme mood swings, irritability, restlessness, irritability, feeling sad, tired or easily tired, loss of interest in likes to do things, distance from family members and friends, difficulty of giving focus and concentrating on something, loss of interest in favorite things, and desire to increase alcohol or tobacco use. All of these elements can be studied and investigated empirically through a social science research approach.

\section{Statement of Problem}

The COVID-19 pandemic had an impact on various sections of society. Social stigma can be linked to the impact of the COVID-19 pandemic, including on people who have been infected, their family members and other health and front-line workers. Action must be taken to address stigma at all phases of the COVID-19 emergency response.

During the MCO period of COVID-19, many were depressed either mentally, emotionally or psychosocially. Among such stressors are the risk of being infected and infecting others, 
especially if the mode of transmission of COVID-19 is not one hundred percent clear, common symptoms of other health problems (e.g. fever or cold) can be mistaken for COVID-19 and cause fear of being infected, mother or father may feel anxious because their children are in dormitories or rented houses for not getting proper care and support, the risk of deterioration in the physical and mental health of vulnerable individuals, for example older adults, those at high risk and the disabled (Shahriarirad et. al., 2021)

During a COVID-19 pandemic, a person can experience symptoms of anxiety and panic due to lack of information or facts, fake news, social media influence, fear and anxiety about a disease that can strike and evoke strong emotions. Effective methods of coping with emotional stress and feelings will make individuals, their loved ones and the whole society stronger. These feelings can be normal if a person responds positively and thinks positively in a conducive environment and is accompanied by the best possible health care (Salari, N., Hosseinian-Far, A., Jalali, R. et al., 2020).

\section{Research Questions}

The research questions are as follows:

1. What is the reality of campus life of Kolej Canselor (KC) students, Universiti Putra Malaysia during the Movement Control Order (MCO) from 18 March 2020 to 14 April 2020 ?

2. What is the value of patience, level of mental well-being among KC students during the period of Movement Control Order (MCO) Covid-19?

3. What is the level of psychosocial well-being of KC students of Universiti Putra Malaysia (UPM) during the period of the Movement Control Order (MCO) Covid-19?

\section{Research Objectives}

The objectives of the study are as follows:

1. To identify the level of patience value among students of the Kolej Canselor of Universiti Putra Malaysia (UPM) during the period of Movement Control Order (MCO), Covid-19.

2. To identify the level of emotional well-being of students of Kolej Canselor, Universiti Putra Malaysia (UPM) during the period of Movement Control Order (MCO), Covid-19.

3. To identify the level of psychosocial well-being of students of the Kolej Canselor, Universiti Putra Malaysia (UPM) during the period of the Movement Control Order (MCO), Covid-19.

\section{Literature Review}

According to the International Federation of Red Cross and Red Crescent Societies (2020), in any pandemic outbreak, it is common for individuals to feel depressed and anxious. Common perceptions of people affected by an outbreak both directly and indirectly may include fear of falling ill and dying, avoiding approaching health or care facilities for fear of being infected while in treatment, fear of losing livelihood, not being able to work during isolation, and being laid off work, fear of being socially isolated or quarantined for being associated with the disease, feeling helpless to protect a loved one and fear of losing a loved one to a virus, fear of parting with a loved one, unwillingness to care for an unaccompanied or separated minor, the disabled or the elderly for fear of being infected, feelings of helplessness, boredom, loneliness and depression due to isolation and finally, fear of reliving experiences during an outbreak of disease or pandemic. 
During the MCO period of COVID-19, many were depressed either mentally, emotionally or psychosocially. Among such stressors are the risk of being infected and infecting others, especially if the mode of transmission of COVID-19 is not one hundred percent clear, common symptoms of other health problems (e.g. fever or cold) can be mistaken for COVID-19 and cause fear of being infected, parents may feel anxious because their children are in dormitories or rented houses for not getting proper care and support, the risk of deterioration in the physical and mental health of vulnerable individuals, for example older adults and people with disabilities.

According to the Malaysian Ministry of Health (2020), during a pandemic, any individual may be emotionally affected as happened during the COVID-19 crisis. Everyone will react differently according to the stressful situation. How a person responds to a pandemic is often influenced by the background of the individual, society, culture and environment. It is common for individuals to feel depressed, worried and anxious. Fear and anxiety about COVID-19 can overflow and evoke strong emotions in any individual.

Following the COVID-19 pandemic, general perceptions suggest that people who may be affected by it may differ from one person to another. These include worries about the possibility of their family members becoming infected, fear of getting sick and dying and losing loved ones, helplessness, not being able to protect loved ones, stress and anxiety especially from being separated from loved ones and caregivers due to quarantine, fear of being placed under supervision. authorities, avoiding health facilities for fear of being infected while in care, anxiety of being detained by police for violating MCO restrictions, fear of not being able to work during segregation, fear of being fired, feeling helpless, boredom, loneliness and depression due to isolation (Morales-Rodríguez, 2021).

Persistent fear, anxiety, uncertainty and stress in a population during a COVID-19 outbreak can cause long-term consequences in vulnerable communities, families and individuals. Among them are the deterioration of social and economic networks, stigma against surviving patients resulting in rejection by society, possible emotional state, anger and placing blame on the government, possible parental anger towards children, spouses, partners and family members (increased family violence and intimate partners), possible distrust of information provided by the government and other authorities and people with pre-existing mental and emotional health disorders or experiencing stress as a result of difficulty obtaining welfare assistance, health facilities or their emotional or physical needs. Some of these fears and reactions stem from realistic dangers, but many of these reactions and behaviors are also caused by lack of knowledge, rumors and misinformation (Merten et.al., 2020).

The psychological effects encountered while living indoors and spending most of the time indoors can cause different psychological effects depending on how a person reacts to the situation. On the positive side, some can have a positive psychological impact such as improving social relationships with family members living in the same environment. However, for some people, negative psychological effects, for example, are increased stress due to not being able to perform routines and activities outside the home, not being able to see friends, worry and anxiety due to not being able to be physically present for example; to help loved ones, helplessness, boredom, loneliness and depression (Sundarasen et.al., 2020). 
Mental health is part of an individual's overall health. Signs that indicate that a person's mental health is affected and in need of psychosocial support. One can monitor their own mental health. Whether mental health is good or not depends on symptoms such as drastic changes in sleep patterns (e.g. insomnia), changes in appetite, extreme mood swings, irritability, restlessness or irritability, feeling sad, tired and easily fatigued, loss of interest in favorite things to do, distance from family members and friends, difficulty concentrating or giving focus, loss of interest in favorite things, desire to increase alcohol or tobacco use.

Social stigma can be associated with COVID-19, including against people who have been infected, their family members and other health and front-line workers. Steps must be taken to address stigma at all phases of the COVID-19 emergency response. Care should be taken to promote the integration of people who have been exposed to COVID-19 without overtargeting. In a more positive context, most people may have positive experiences such as trying to find ways to overcome internal psychological and resilience problems in the face of a COVID-19 outbreak, community members may cooperate better and one may find more satisfaction in being able to help others.

Students who were "locked up" at the university during the COVID-19 pandemic had to maintain social contact with parents, relatives, and friends by using smartphones, texting, listening to the radio and sharing key factual messages in the student community using social media. The Student Affairs Division takes care the welfare and needs of students in various ways so that they can get attention and support because they have been separated from their families and guardians.

Student learning process also involves transformation of extensive use of e-learning, virtual lectures, diversifying the use of various "virtual meeting" applications such as Google Meet, Zoom, Webex, Streamyard, Google Team, Whatsapp, Telegram and email applications as well as PutraBlast.

There are a total of 2,367 UPM students at the Serdang and Bintulu campuses, Sarawak as well as about 1,200 students staying off campus during the MCO period starting on March 18, 2020. Food aid is continuously distributed to students from the first phase of the MCO to the third phase. Food aid is provided free of charge three times a day as well as personal items. This is to ensure that students remain in their respective residential colleges and maintain health and safety. UPM also provides dry food assistance for cooking as well as personal items to off-campus students. In addition, the grocery store at the Kolej Canselor and Kolej Pendeta Zaaba are open throughout the day to give students the opportunity to buy necessities and goods. The University Counseling Division has established a special line for students to seek counseling services directly during the MCO period. The management of Universiti Putra Malaysia also constantly monitors the condition of its students on and off campus, taking care of their welfare, needs, health and safety.

Everyone was sympathetic and focused on the students who were still on campus during the MCO period. In this fast-paced era of information technology and social media, students and parents can use both to connect with each other. Many applications can be used to realize this noble desire, for example Google Meet, Whatsapp Video Call, Skype, Zoom and Face Time (IPhone). 
Parents, on the other hand, need to play a role in contacting and always communicating with their children so that they will always persevere through the test during the MCO period and give words of advice and encouragement to their children.

\section{Scope of Research}

The main scope of the research involved UPM students living in the Kolej Canselor during the Movement Control Order (MCO) to curb the transmission of corona virus (COVID-19). This study will focus on Kolej Canselor students only and does not cover other colleges. This is due to cost factors, time and financial implications. The respondents consisted of students living in the Kolej Canselor during Movement Control Order (MCO). It is almost impossible to take information from all public university students to participate in this research. Therefore, a sampling framework will be formed and directed to the objective requirements of the study.

\section{Design and Sample Size}

The study design will take into account data and information related to UPM students living in the Kolej Canselor during the Movement Control Order (MCO) to curb the spread of corona virus (COVID-19). The names, mobile phone numbers and email addresses of these students were obtained from the Student Affairs Division, UPM.

The sample size is based on the entire population of UPM students during the MCO period. Based on the information slide of UPM Students in Serdang Campus Residential College and Bintulu Campus (18 May 2020), there were 1,377 (10.4 \%) students during the MCO period out of 13,210 UPM students for Serdang Campus while for Bintulu Campus, there were 901 $(77.4 \%)$ out of 1,164 students. The total number of students during the MCO period was $2,278(15.8 \%)$ out of a total of 14,374 UPM students staying in residential colleges. While Kolej Canselor students during the MCO period was 202.

Data and information will be collected based on documentation studies, existing policies, legal documents, archives, manuscripts and the main method is through the distribution of online questionnaires. The sample in this study is a community of UPM students living in the Kolej Canselor during the Movement Control Order (MCO) to curb the spread of corona virus (COVID-19).

This study has identified the level of mental, emotional and psychosocial well-being of KC, UPM students living in their respective residential college during the Movement Control Order (MCO) to curb corona virus transmission (COVID-19) based on a study in a simplified sampling group. This method is a strength as it confirms a general statement on the level of mental, emotional and psychosocial well-being among students in a larger group of institutions of higher learning in Malaysia. While this is a possibility, the truth cannot be ruled out.

\section{Sampling Framework}

The sampling framework will be strengthened so that it represents the level of mental, emotional and psychosocial well-being of UPM students living in KC during the Movement Control Order (MCO). Therefore, the validity and reliability of the study findings will be able to be correlated with the level of representativeness of the sample. 
The measure of dependent variables covered the level of mental, emotional and psychosocial well-being of KC, UPM students living in the college during the Movement Control Order (MCO) while the independent variables covered knowledge, understanding and attitudes towards mental, emotional and psychosocial well-being of UPM students living in Kolej Canselor during Movement Control Order (MCO). As already explained, the data were analyzed quantitatively and descriptively.

\section{Research Methodology}

This study is more in the form of quantitative research. The descriptions in this study are more of a descriptive quantitative form. The research methodology involved online questionnaire distribution methods and library research.

\section{Definitions in Terms of Linguistic}

\section{The Value of Patience}

The value of patience means at ease while enduring suffering, pain, hardship and so on, not in a hurry to calm down. It also includes the meaning of not easily angry or not easily discouraged and strong in the face of pain, challenges, obstacles and others. In other words, a person is said to be patient if he is calm in the face of trials and tribulations.

\section{Mental and emotional health}

Mental and emotional health refers to mental well-being as the manifestation of a significant form of behavioral or psychological pattern related to life, joy, happiness, not being sick, not being disabled and having freedom in life. It is a response from a culturally agreed state of well-being, such as rejoicing in success and a sense of happiness with a loved one. It is considered a sign that a behavior, psychology, or biology is functioning well (Lippincott Williams \& Wilkins, 2009).

\section{Psychosocial support}

This terminology refers to support and encouragement related to psychosocial or involving psychological and social factors or influences.

\section{Operational Definitions}

In terms of the operational definition, the value of patience means the resilience of students in withstanding any challenge, challenging situation, suffering, pain, hardship and calm, not easily discouraged and strong and tranquil in the face of any tests and trials. The operational definition of "mental health, emotional and psychosocial support MEPP)" in the postMovement Control Order (MCO) and COVID-19 context will be used in describing any type of social support whether directly or indirectly intended to protect or promote mental, emotional and psychosocial well-being or prevent or treat mental and emotional health conditions.

In the context of this study, what is important is the response of UPM students to post emergency situations such as the COVID-19 pandemic in health, social life, learning, campus life and community environment. 


\section{Types of Online Research}

At least there are eight types of online research. Web-based research, web-based survey or online research are methods conducted using the internet. These methods are appropriate in areas such as psychology and economic behavior. However, these methods can also be found in a various social science disciplines including sociology, political science and anthropology (Hooley, Marriott \& Wellens, 2012). Second, social network analysis and online research. Social network analysis is a study to evaluate, measure and map the relationships between informed entities to identify and improve problems through online research (Koçak, 2014). It carries the meaning of something that has its own existence, things, objects, individuals, people, events and so on.

Third, cyber ethnography or netnography This research method explores how humans live and interact online through a variety of different research strategies in order to achieve the research objectives (Kozinets, 2010). Fourth, online content analysis. According to Chuang et al. (2014), online content analysis is often used in social sciences and humanities, communication, psychology, and human-computer interaction. This study refers to the use of a collection of research techniques to describe and draw conclusions of online material through systematic coding and interpretation.

Fifth, online focus group. Online focus group considers the use of online focus groups as a method for conducting qualitative research in the social sciences. The main purpose of the online focus group is to find answers to research questions via online. This method is an expensive method as compared to other qualitative research methods. This method is seen as suitable for consumer research, business research and political research (Stancanelli, 2010). Sixth, online interview is a study of using data collected through online interviews and follow the fundamental procedures (Salmons, 2014). Furthermore, an online interview is an online research method conducted using computer-mediated communication such as instant messaging, email, or video.

Seventh, online survey or also known as online questionnaire. Online surveys are a commonly used strategy for obtaining data and information as well as often seen as cost effective in terms of time and resources required. Better access to computers and the Internet make researchers and respondents more comfortable to use online survey (Harlow, 2010). Many experts are of the opinion that the practical strategies that proved effective in engaging respondents in an online survey process and in managing online responses are discussed and considered in the light of Covid-19 pandemic.

Eighth, online qualitative research. It involves undertaking qualitative research with the variety of populations. According to Neville, Adams and Cook (2016), using the internet to collect qualitative data offers additional ways to gather qualitative data over traditional data collection methods. The use of alternative interview methods may encourage participation of vulnerable participants. Traditional and common modes of collecting qualitative data with these groups have been via face-to-face recorded interviews. This type of research uses email, synchronous online interviews and an online qualitative survey. It has its own strengths and limitations. However, the use of these internet-based data collection methods may encourage researchers to embrace technology and move away from using traditional face-to-face interviews when researching with vulnerable populations. It is a complex and challenging 
process for researchers. According to Hewson (2010). Internet-mediated research has its potential role in facilitating mixed methods research. Email interview also is one of the elements of online qualitative research (Hunt and McHale, 2007).

Before the Covid-19 pandemic struck, face-to-face research method were frequently used in research. Methods of interviews, distribution of questionnaires and so on are done face to face. Distributing and collecting questionnaire forms may take a longer duration as compared to online research methods. Data analysis also may take a longer time as compared to online methods. The survey tools which are usually used in the online research were questionnaire forms, interview questions using the Google Form, SurveyMonkey and other platforms. Questionnaires are distributed online through social media such as Whatsapp, Facebook, Instagram and other applications due to movement control order during the Covid-19 pandemic. In addition, questionnaires were also distributed to the target population through email platforms and websites.

Online questionnaires are one of the instruments used to collect data for a study via the Internet. Methods of data collection through online questionnaires are seen as relevant nowadays especially during the Covid-19 pandemic. The online questionnaire allowed the respondents to maintain their privacy and providing comfort while answering the questionnaire as well as avoiding implications of the Covid-19 pandemic. The immediate advantage of using online research methods is that it can expand access to new populations that could not be reached before. The data collected has a diversity of information in terms of race, background and social status. The large sample size helps in providing more accurate information and reducing sampling errors for a study.

The use of online questionnaires can save money and time. Researchers no longer have to print questionnaires and wait for questionnaires to be returned. One of the factors that slows down a study is the data collection process. When using traditional data collection procedures, the researcher searches for appropriate respondents and collects data through them. Collecting data may take weeks depending on the number of respondents desired. Online research methods help researchers to collect data from the respondents, even thousands of respondents in a short time. Information and data can be obtained automatically and can be accessed at any time. It is easy to transfer into SPSS software for data analysis process. The Internet now (such as Google Form) provides easy access to most inexpensive survey software, as well as to millions of potential survey respondents, and it has lowered costs and other barriers to conducting surveys. Questionnaires can be placed on the website or sent directly to respondents via email. It can save time and it is a practical method as compared to the traditional method.

Phase 1 involves a literature review process in finding literature related to the Covid-19 pandemic in general, elements of mental, emotional and psychosocial well-being among the community and students and aspects of the Covid-19 Movement Control Order (MCO) in Malaysia in particular and in the world in general. This process will help researchers to identify and understand the fundamental issues of the study, subject matter as well as the main focus of research.

Phase 2 of the research process involved the construction and drafting of an online questionnaire. Key issues are discussed and summarized. Then a draft questionnaire was 
drafted before being discussed collectively among the researchers before the actual questionnaire was determined.

Phase 3 involved a pre-test session of the questionnaire conducted among 120 students of Kolej Canselor, Universiti Putra Malaysia. The questions asked to the respondents were tested with the aim that the respondents could understand the questions and answer them well. In addition, the pre-tests that have been conducted on the questionnaires are to ensure that the questions have a high level of validity and reliability and as a result, the results and data obtained can no longer be disputed or refuted. The pre-test session will produce changes and improvements to the questions in addition to identifying the level of reliability of the questions. Level of reliability was based on Cronbach Alpha analysis. A pre-test session of the instrument was conducted before the actual questionnaire is distributed. The purpose was to correct any typographical errors, errors in language and sentence structure, question form and questionnaire structure. It also aims to make improvements before the actual survey is conducted.

Phase 4 involves the process of registering research through Google Form which is free of charge. Upon completion of registration, the process of entering the questionnaire into Google Form was done until fully completed.

Phase 5 involved the collection of emails from the students involved and emailed links from Google Form to the respondents.

Phase 6 is a data collection process where the online questionnaire collection process was conducted among all students who are in the Kolej Canselor UPM campus during the MCO period that has been stated in the scope of the study.

\section{Location of the Study}

This study covers the Kolej Canselor, Universiti Putra Malaysia campus, Serdang, Selangor. This location was chosen since the researcher is the Principal of Kolej Canselor, Universiti Putra Malaysia and easy to access and communicate the students of Kolej Canselor.

\section{The Method of Data Collection}

The method of data collection through online questionnaires has an advantage in terms of speed where according to a given period, the time required to complete an online survey project is on average two-thirds shorter than traditional research methods. Because the information was collected automatically, the researchers did not have to wait for the questionnaire to be returned while the response period was only short. In other contexts, using online questionnaires will reduce research costs. Researchers will save money and not have to allocate time and resources to enter information into a database. Normal responses are processed automatically and the results can be accessed at any time. At the same time this method is more accurate. The margin of error can be reduced because respondents are able to enter their responses directly into the system.

In addition, the analysis can be speeded up because the results of the online survey can be completed at any time. At the same time, the findings of the study are generated in real time so that researchers can act quickly, create graphics for reporting, export the data for further analysis and share the findings of the study with anyone. This method is also easy to practice 
by the respondents. The majority of those with Internet access would rather answer online surveys than use traditional or telephone questionnaires. With the online survey method, respondents were able to choose the time that best suited them and the time required to complete the survey was much shorter and faster. This method is also easy to use by researchers. The main benefit of online surveys is that researchers can increase productivity by saving time. Data is available immediately and can easily be transferred into specialized statistical software or spreadsheets when more detailed analysis is required.

Hence, online surveys are an opportunity to increase the effectiveness of actual research. In addition, this method would create an atmosphere where respondents would rather complete an online survey than participate in a written questionnaire or telephone interview and usually provide longer and more detailed answers. By planning and sending relevant surveys to the target group, respondents are more likely to respond with honest answers. This method is also more flexible where the sequence of queries in an online survey can be changed depending on the priority of each question. In this way, the survey can be tailored for each respondent. In short, online surveys are the best option for such research, are less time consuming, cheaper, the results are faster, and researchers are able to transfer and use data in a variety of applications to answer important questions. The strength of the response and what the respondents surveyed online are capable of obtaining information directly and what is more important, it is more accurate.

\section{Data Analysis}

Phase 7 involves the process of data analysis. In this phase, the primary and secondary data are analyzed and integrated. Data from the online questionnaire were analyzed according to the following themes:

1. The value of patience of Kolej Canselor (KC) UPM students

2. Mental and emotional well-being of KC UPM students

3. Psychosocial well-being of KC UPM students

4. Comments from KC UPM students on the issues highlighted.

The results of the literature review are combined with quantitative data and then processed and analyzed, conclusions are drawn and finally a study report is prepared.

\section{Study Findings and Analysis}

The value of patience among Kolej Canselor, Universiti Putra Malaysia (UPM) residential college students during the Covid-19 Movement Control Order (MCO) period is very good. Otherwise, surely some bad things will happen.

Furthermore, the level of emotional well-being and the level of psychosocial well-being among KC students of Universiti Putra Malaysia (UPM) after the Covid-19 Movement Control Order (MCO) period will be discussed.

The Kolej Canselor has nine blocks, namely Malinja Block, Masria, Mahsuri, Murni, MSN, Cermai, Salak, Keranji and Delima with a capacity that can be filled is 1421 students. During the intended MCO, a total of 137 students were in the $\mathrm{KC}$ with breakdowns in Keranji Block (21.2\%), Delima (22.6\%), Cermai (17.5\%), Murni (9.5\%) and Mahsuri (8.8\%). While in the other 
blocks there are no occupants. The following is relevant information presented in the form of a pie chart.

\title{
Chart 1: Percentage of Students Living in the Kolej Canselor Residential Block, UPM
}

\author{
6. Block \\ 137 responses
}

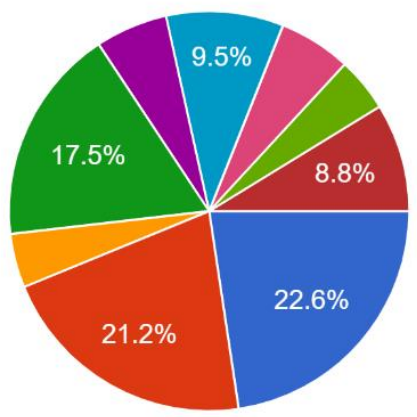

Overall, among the respondents, 33.6\% were first year students, $22.6 \%$ second year students, $19 \%$ third year students and $24.8 \%$ fourth year students.

\section{Chart 2: Percentage of Students Living in the Kolej Canselor Residential Block During MCO} by Year of Study

9. Year

137 responses

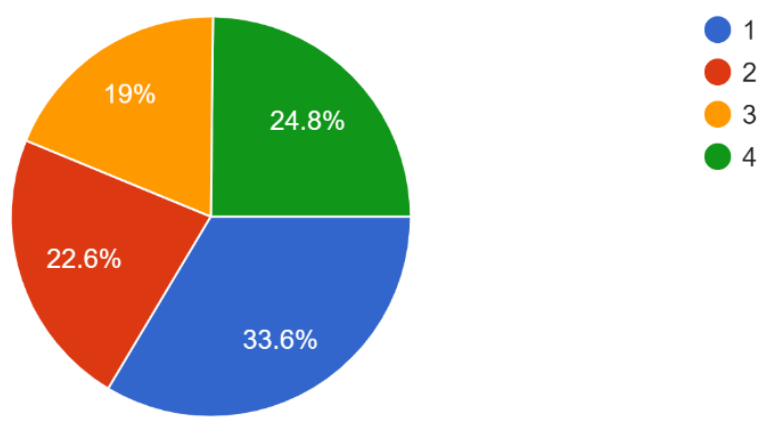

A total of $24.1 \%$ of the respondents stated that they felt depressed during the MCO while 75.9\% stated that they did not feel depressed during the MCO. This fact indicates that most of the respondents have high resilience and are likely to feel safe especially when in $\mathrm{KC}$ especially when their welfare and foods, and drinks are taken care of. 


\section{Chart 3: Percentage Of Students Who Do Not Feel Depressed in Kolej Canselor During}

10. Do you feel depress during MCO?

137 responses

MCO

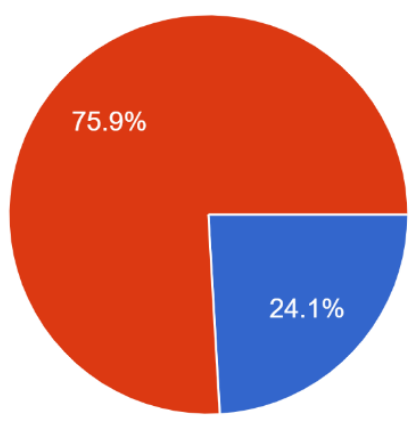

As noted above, as many as $24.1 \%$ of respondents stated that they felt depressed during the MCO. In terms of stress levels, $81 \%$ of respondents stated that their stress levels were low, 15.3\% respondents stated that their emotional stress levels were moderate and $3.6 \%$ respondents stated that their emotional stress levels were high (Chart 4).

As we know, during the MCO period, various unprecedented uncertainties and fears arose abruptly among students at university campuses. Measures taken by university authorities to reduce the risk of virus spread such as health screening, residential quarantine and physical incarceration, on the one hand, are desirable for students to feel anxious, sad, scared and isolated. When students face crises like this that threaten health, safety and life, fear, emotional stress and anxiety are inevitable due to the occurrence of the natural response of the mind and body to danger and uncertainty about what is to come. Similarly, feelings of sadness, loneliness and emotional stress are natural responses to a loss and the occurrence of isolation (confined or quarantined).

Furthermore, many experience changes in appetite, sleep, relationship difficulties, challenges with focus and concentration, irritability, frustration, boredom and so on. There are a variety of reactions that can be seen in response to abnormal conditions.

Despite experiencing some of these feelings, the counseling services provided by the UPM Counseling Division may be beneficial. Difficulty focusing that affects a student's ability to fulfill his or her duties, difficulty waking up from sleep or not receiving calls from family or friends also indicate difficulties that may require additional support from a counselor.

After a few months have passed, students with low or moderate mental health have be monitored by university authorities. Symptom monitoring by the UPM Counseling Division and the University Health Center is important while for students, if new symptoms of emotional stress appear or worsen, they should immediately see a counselor or doctor even a psychiatrist. 
Thoughts about suicidal acts, the urge to self-harm, despair or helplessness and engaging in risky behaviors such as increased use of alcohol and illicit substances such as drugs affecting student lives, are also a viable indication that additional help is needed.

\section{Chart 4: Percentage of Students Showing Depressive Stress Levels During MCO}

11. If yes, what are the level of you depression?

137 responses

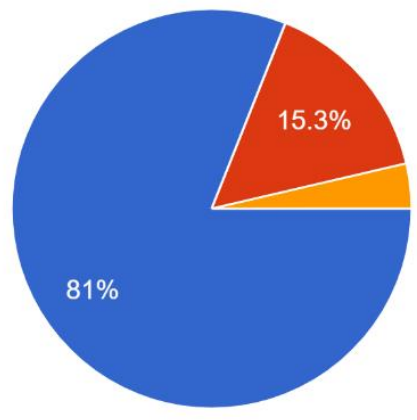

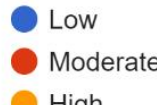

High

We also asked students feelings about the concern that something bad would happen during the MCO. A total of $54.7 \%$ of respondents stated that they felt something bad would happen during MCO, while $42.3 \%$ stated that they had never had such feelings and the rest (3\%) stated that they always felt something bad would happen during MCO (Chart 5).

Chart 5: Percentage of Students Who Show a Level of Feeling Something Bad Will Happen During an MCO

12. During $\mathrm{MCO}$, I feel something bad will happen

137 responses
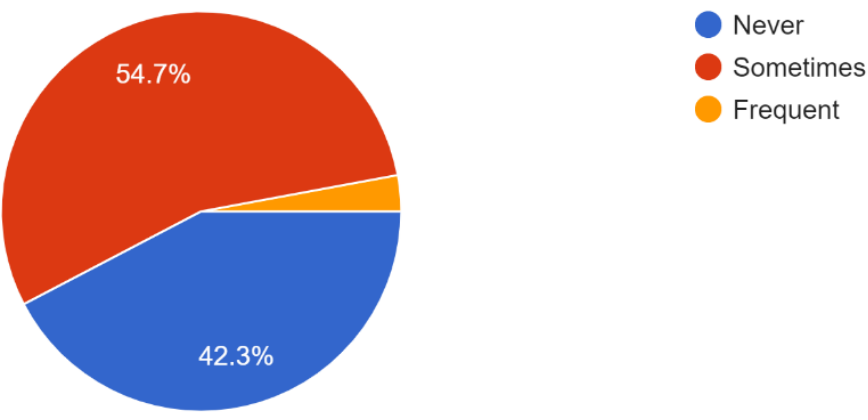

During a pandemic, a person may feel overwhelmed, sad and experience high levels of anxiety. Anxiety can cause chest pain and other physical symptoms. However, it is unlikely that students are worried that they are symptomatic of Covid-19. This is excepted for concerns about parents, relatives or siblings who are in their respective hometowns.

Feelings of worry and restlessness can cause physical pain symptoms, such as difficulty breathing, chest pain, nausea and vomiting, diarrhea, headache, fatigue, chills, rapid heartbeat, trembling and sweating without fever. 
We think students may find the Covid-19 pandemic does not cause anxiety and distress because they are in a safe campus area despite being confined. This is because, emotional stress and anxiety during a pandemic, if not controlled can exacerbate the existing mental health condition of students. The fact of concern for the health of their loved ones may exist. But what is more important is the health of the students themselves that they need to take care of and nurture.

We also asked the level of students feelings of despair during the MCO. A total of $62.8 \%$ of respondents stated that they never felt despair during MCO, while $33.6 \%$ stated that they sometimes had such feelings and the rest (3.6\%) stated that they always felt despair during MCO (Chart 6).

As we have explained, Covid-19 affects the mental health and physical health of a student. The level of anxiety and despair of KC students is not significant although well-founded concerns can be placed.

We have no evidence to associate levels of anxiety with attitudes of despair. This factor of despair may be linked to financial problems or even confined realities although this is not always true. Even so, we did not rule out factors influencing anxiety, despair and individuals who may have been more psychologically affected during the outbreak. We believe significant action can be taken to protect student health by ensuring that psychosocial interventions for students can be planned in advance.

\section{Chart 6: Percentage of Students Who Show Levels of Feelings of Despair During MCO}

13. During MCO, I feel hopeless

137 responses

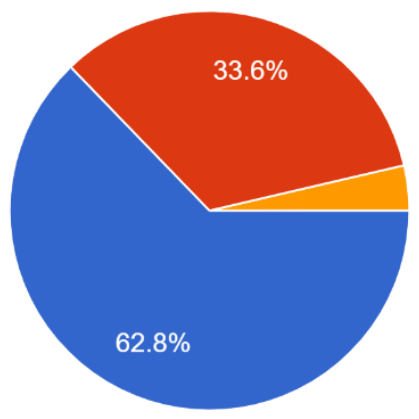

Never

Sometimes

Frequent

We also asked the students' desire to return to their hometowns if allowed by the university authorities after 14 April 2020. A total of $49.6 \%$ of respondents stated that they still want to live in $\mathrm{KC}$ while $48.2 \%$ stated that they would like to return to their hometowns as soon as possible. $2.2 \%$ of students stated that they would like to stay off campus with friends (Chart 7).

There were 44 respondents who expressed their respective expressions of feelings in the Google Form distributed. Some of the students expressed hope to be sent back to their hometowns. Among them, we quote: "If possible please provide us a free bus like the early time plan of MCO that day", "Please let me go back home...", "I want to go back home and sponsor my ticket please $\mathcal{\Omega}^{\circ}$ ", "Once the MCO ended, I really really really hope to be able to go back home as soon as possible as my parents, especially my mom, is worried and sicked of 
me ", "If the government grants permission, I will return home. If the dry food still avaiable, please give me more", "If it is better to stay, may be we can think about it. Otherwise, provide us transportation so that we can travel to our hometown "I DON'T KNOW WHAT TO SAY. THANKS" $=$ ".

There are also students who ask to go out to Sri Serdang to buy daily necessities. Among them: We quote: "Please allow us to go out to buy necessary stuff for the time being. We appreciate your cooperation and services. Thank you \& Jazak'Allahu Khair ", "Please let us go out as the government sets out rules which is allowed to go out for buying food or daily supplies", and "More dry food supplies. Update us promptly. If the MCO extended, what will UPM do for us?".

There are also students who are good at thanking the management of the Kolej Canselor. Among them, we quote: "Nope. Thanks for providing us foods. KC is always the best. Thanks again! Everything is okay", "Nothing. Just want to say thank you so much for taking care of the students. May God bless you, your family members, and everyone that has been with us since day one", "Thanks! Principal of Kolej Canselor for managing all the needs of residents here. The student leaders are also very helpful. I don't feel helpless rather feeling homely. I extend my heartfelt gratitude to all who are working relentlessly for our betterment. Just for information wanna know that how many days to stay here in KC?, and when we can get back to K10?", "Thank you so much for taking care of my welfare here (-)", and "Thank u for taking care of us during mco. My family and I really appreciate it. May Allah bless all the people that involved. thank $u$ (?)"

All of these written comments show strength in voicing very strong opinions and feelings when facing MCO in the wake of the Covid-19 pandemic. Of course, it manifests the intellect hidden in the hearts and souls of the students.

\section{Chart 7: Percentage of Students Who Show Desire To Return To Hometown as Compared To Living In KC}

14. After April 14,2020, if permitted, your consideration is to 137 responses

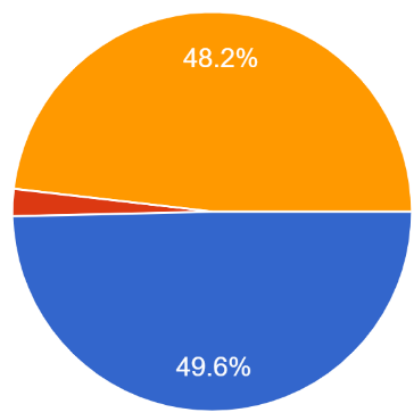

stay in Kolej Canselor

stay off campus with friends

go back to home town as soon as possible

leave this country

\section{Conclusions, Implications of the Study and Recommendations}

This study is about the campus life of Kolej Canselor (KC) students, Universiti Putra Malaysia during the Movement Control Order (MCO) from 18 March 2020 to 14 April 2020. Aspects 
examined are the value of patience, level of mental, emotional and psychosocial well-being among KC students during the period of the Covid-19 Movement Control Order (MCO). A diverse and complementary approach in providing appropriate support is essential for students in continuing their survival as students. During the COVID-19 MCO period, many were depressed either mentally, emotionally or psychosocially. This depends on the value of a student's patience and mental resilience. This study found that $24.3 \%$ of students felt depressed during the period. $13.7 \%$ of respondents stated that their level of depression was high. Interestingly, $47.8 \%$ stated that they would like to return to their hometown if allowed.

The stakeholders relevant to this study are the students themselves, academics, Universiti Putra Malaysia, Ministry of Higher Education Malaysia, Ministry of Health Malaysia, Ministry of Home Affairs, National Security Council and the Malaysian government.

As no other study like this has been conducted in Malaysia, as far as it is known, then this study is a fundamental research in the academic world. The impact of this research refers to the way research influences various new phenomena and trends in society, especially the student community. In this context is the level of mental, emotional and psychosocial wellbeing among UPM students living in the Kolej Canselor (KC) during the Movement Control Order (MCO) to curb the spread of corona virus (COVID-19). The impact of this study will manifest the results of a combination of new and appropriate research findings involving various factors that can be used in the future as well as a useful literature for academia in particular and society in general.

Research influences society through knowledge and worldview. The scientific knowledge and procedures used by social science researchers influence the way many individuals in society think about themselves, others, and their environment. Therefore, the impact of this scientific research on society is very high if disseminated through various platforms and media.

This study is a new study involving the pandemic of corona virus transmission (COVID-19). As there is no such study conducted in Malaysia, then this study is a research that contributes significantly to the country either directly or indirectly in the future in the context of policies, SOPs, and guidelines especially the Ministry of Home Affairs, Ministry of Health Malaysia, Ministry of Higher Education Malaysia and others in general.

In the context of this study, we will gain a new knowledge and information about the level of mental, emotional and psychosocial well-being among UPM students living in the Kolej Canselor during the Movement Control Order (MCO) to curb corona virus transmission (COVID-19). This is because Covid-19 is a new virus. The validity and reliability of the study findings will be able to be correlated with the level of representativeness of the sample.

At least we have the experience of dealing with and managing students during the Covid-19 pandemic. This study can be used as a platform for Universiti Putra Malaysia and the Ministry of Higher Education Malaysia to make well preparation as well as to formulate new SOPs in the event of another pandemic in the future.

\section{References}

Chuang, J., Wilkerson, J. D., Weiss, R., Tingley, D., Stewart, B. M., Roberts, M. E., ... \& Heer, J. (2014, December). Computer-assisted content analysis: Topic models for exploring 
multiple subjective interpretations. In Advances in Neural Information Processing Systems workshop on human-propelled machine learning (pp. 1-9)..

Hankins, M. S. (2015). International Federation of Red Cross and Red Crescent Societies. Mental Health and Psychosocial Support for Staff, Volunteers and Communities in an Outbreak of Novel Coronavirus. IFRC: Hong Kong, 2020.

Harlow, A. (2010). Online surveys-possibilities, pitfalls and practicalities: the experience of the TELA evaluation. Waikato Journal of Education, 15(2), 95-108.

Hemphill, J. C. (2001). Mental Health [Review of Chapter 16 for the Book Medical Terminology Made Incredibly Easy]. Medical Terminology Made Incredibly Easy. Ambler, USA: Lippincott Williams \& Wilkins.

Hewson, C. (2010). Internet-mediated research and its potential role in facilitating mixed methods research. Handbook of emergent methods, 543-570.

Hooley, T., Wellens, J., \& Marriott, J. (2012). What is Online research?: Using the Internet for social science research. A\&C Black.

Hunt, N., \& McHale, S. (2007). A practical guide to the e-mail interview. Qualitative health research, 17(10), 1415-1421.

Inclusiva, O. N. G. (2020). Recommendations for health protection of people with disabilities during outbreaks: Lessons learned from the 2019 Novel Coronavirus. ONG Inclusiva.

Inter-Agency Standing Committee. (2020). Interim Briefing Note. Adressing Mental Health and Psychosocial Aspects of COVID-19 Outbreak. Version 1.5.

Koçak, N. G. (2014). Social networks and social network analysis. International Journal of Business and Social Science, 5(2), 126-135.

Kozinets, R. V. (2010). Netnography: the marketer's secret weapon. How social media understanding drives innovation. Market Research Bulletin.

Mertens, G., Gerritsen, L., Duijndam, S., Salemink, E., \& Engelhard, I. M. (2020). Fear of the coronavirus (COVID-19): Predictors in an online study conducted in March 2020. Journal of anxiety disorders, 74, 102258.

Morales-Rodríguez, F. M. (2021). Fear, Stress, Resilience and Coping Strategies during COVID19 in Spanish University Students. Sustainability, 13(11), 5824.

Neville, S., Adams, J., \& Cook, C. (2016). Using internet-based approaches to collect qualitative data from vulnerable groups: reflections from the field. Contemporary Nurse, 52(6), 657-668.

Hayati, N. E. (2021). PKP: Kebajikan pelajar jadi keutamaan. Retrieved from https://www.bharian.com.my/berita/nasional/2020/04/678115/MCO-kebajikanpelajar-jadi-keutamaan.

Salari, N., Hosseinian-Far, A., Jalali, R., Vaisi-Raygani, A., Rasoulpoor, S., Mohammadi, M., ... \& Khaledi-Paveh, B. (2020). Prevalence of stress, anxiety, depression among the general population during the COVID-19 pandemic: a systematic review and metaanalysis. Globalization and health, 16(1), 1-11.

Salmons, J. (2012). Designing and conducting research with online interviews. Cases in online interview research, 1-30.

Shahriarirad, R., Erfani, A., Ranjbar, K., Bazrafshan, A., \& Mirahmadizadeh, A. (2021). The mental health impact of COVID-19 outbreak: a Nationwide Survey in Iran. International journal of mental health systems, 15(1), 1-13.

Stancanelli, J. (2010). Conducting an online focus group. The Qualitative Report, 15(3), 761.

Sundarasen, S., Chinna, K., Kamaludin, K., Nurunnabi, M., Baloch, G. M., Khoshaim, H. B., ... \& Sukayt, A. (2020). Psychological impact of COVID-19 and lockdown among university 
students in Malaysia: implications and policy recommendations. International journal of environmental research and public health, 17(17), 6206.

WHO. (2020). Mental health and psychosocial considerations during the COVID-19 outbreak. Retrieved from https://www.who.int/docs/default-source/coronaviruse/mentalhealth-considerations.pdf 